\title{
EDEECONOMIAE 풀NEGÓCIO
}

ISSN impresso: 1679-1614

ISSN online: $2526-5539$

Vol. 17 | N. 1 | 2019

EDITORIAL

\section{Análise Econômica da Agricultura: Novos Temas Demandam Novos Enfoques?}

\author{
José Maria Ferreira Jardim da Silveira \\ Universidade Estadual de Campinas, Instituto de Economia, Campinas - SP, Brasil. \\ ORCID: https://orcid.org/0000-0003-3680-875X \\ E-mail: jmsilv52@gmail.com
}

\section{Introdução}

O conteúdo da análise econômica se transformou radicalmente nos últimos 30 anos. Temas candentes da relação entre os pares (por exemplo, entre alunos em uma sala de aula), a economia do crime, a dos jogos cooperativos envolvendo decisões interpessoais, o papel das instituições no condicionamento das preferências (as instituições não existem apenas para auxiliar na solução das falhas de mercado), a noção crescente da importância da confiança e o respeito às regras para a criação de um ambiente econômico favorável emergiram e se sobrepuseram ao tratamento estritamente econômico do funcionamento dos mercados, da competição e da competitividade, e até passaram a fazer parte das análises macroeconômicas. Também, a economia agrícola e seus desdobramentos conduziram à formação de um ambiente acadêmico profícuo e variado nos últimos 50 anos. Associações internacionais e revistas de destaque de instituições de pesquisa influentes geraram um debate que, progressivamente, foi incorporando questões como o combate à pobreza e à desigualdade, a regulação da tecnologia, o papel da propriedade intelectual, a análise da interpenetração entre agricultura, indústria e principalmente serviços - inclusive financeiros e tecnológicos - e, notadamente, o papel das cadeias globais de valor.

Todavia, outros novos temas estariam emergindo, criando dificuldades metodológicas, demandando novos enfoques e instrumentos de análise? Ou seria possível revisitar os temas citados acima desenvolvendo e aplicando novos métodos e, com isso, contribuir para transformar a própria teoria econômica?

Vale adicionar uma breve menção à ideia de complexidade. A separação de efeitos é uma das pedras fundamentais da análise econômica, em quaisquer níveis para os quais for definida. O problema é que, cada vez mais, os efeitos 
são resultados de interações entre agentes e não de regras de comportamento baseadas em racionalidade definida ex ante e que devem ser testadas por métodos empíricos. O conhecimento das características dos agentes e de suas regras de comportamento não permite prever resultados, em função de processos interativos que caracterizam a complexidade. A noção de "dinâmica em ambientes complexos" dificulta a definição de regras de ouro, de condições iniciais e finais para a definição de trajetórias, mas cria oportunidades para elaborar modelos de simulação, em que fenômenos emergentes são identificados, para então serem confrontados aos fatos empíricos a eles relacionados.

\section{Redes e Complexidade: uma escalada longa que demanda diálogo interdisciplinar}

Namatame e Chen (2016) apontam que redes de interesse socioeconômico são geradas por meio de diferentes padrões de interação entre agentes, que são heterogêneos. As conexões em redes permitem tratar a heterogeneidade quanto às posições dos agentes na estrutura - considerando centralidade, prestígio, influência e capacidade de fazer fluir a informação e o conhecimento -, assim como calcular o efeito dos pesos de acordo com seus atributos (parcela de mercado, importância no comércio externo, gastos com P\&D, estratégias de patenteamento). Com isso, os processos econômicos podem ser entendidos pelo impacto dos agentes na rede e pelos determinantes da estrutura (cambiável) incidentes sobre a transformação e o reposicionamento desses agentes (considerando que os pesos são exógenos, salvo se os efeitos de redes fizerem parte de um modelo dinâmico).

Para além da análise empírica dos processos, o enfoque de redes, combinado com a ideia de modelos baseados em agentes heterogêneos, permite criar sistemas que dão base à troca de informação e à mudança nos estados dos agentes, dada uma determinada topologia de rede. Assim, é possível entender o que se passa nas redes reais, por exemplo, as de difusão tecnológica. Em resumo, buscam-se modelos que descrevam como o comportamento dos agentes em interação é afetado pela rede e como suas mudanças de estado reconfiguram as redes.

Como foi dito acima, as propriedades que interessam na análise são justamente as que emergem e que podem confirmar ou não fatos estilizados da economia ou mesmo predições teóricas. A análise de redes complexas ajuda a entender o processo: redes com forte assimetria entre os agentes podem gerar dinâmicas muito simples, como um tipo de gravitação permanente, e convergência para estados estacionários, conforme apontado por Goyal (2008) para processo de aprendizado em rede, ou para "atratores" estranhos, como bifurcações ou processos de avalanche. Esses agentes não podem ser retirados da rede que lhes atribuiu importância diferenciada, sob pena de descaracterização de todo o processo (BARABÁSI e ALBERT, 1999; JACKSON, 2008), gerando a própria destruição da estrutura. 
Com base nos trabalhos de Dickinson et al. (2016), Batagelj et al. (2014) e Namatame e Chen (2016), pode-se resumir, da seguinte forma, a escalada relativa às pesquisas com redes de modelos baseados em agentes:

a) Estudos descritivos: permitem identificar indicadores topológicos de redes e, ao mesmo tempo, agentes de destaque, por exemplo, patentes, gatekeepers, inovações-chave, sementes, junções e derivações em trajetórias tecnológicas, bem como formas de cooperação. A lista é grande e os trabalhos se multiplicam. É possível também verificar hipóteses utilizando indicadores de redes em estudos econométricos, como fazem Corredoira e Banarjee (2014), para selecionar aqueles de maior importância em grandes redes de patentes;

b) Modelos baseados em redes e em agentes: há a percepção de que as redes existem, mesmo que não seja de forma explícita, o que nos remete à importância das externalidades de rede, já tratadas em trabalhos de organização industrial. Os avanços realizados permitem identificar gerações de estudos envolvidas em problemas relacionados ao efeito de proximidade, a partir da definição de um espaço regular de vizinhança, ou mesmo em pesquisas nas quais os agentes estão dispostos em formas mais complexas, como nas redes de comércio. Comportamentos de "boiada" de agentes racionais podem se justificar pela ideia de "preferential attachement" (BARABÁSI e ALBERT, 1999), relacionada a modelos em que a decisão de consumir está associada também à adesão a uma rede, de forma que a densidade da rede seja um dos determinantes da curva de demanda (network-based discrete choice models). Com isso, é possível modelar mudanças drásticas na curva de demanda inversa, chamada avalanche (Namatame e Chen, 2016), e efeitos de histerese (que também podem ser estimados econometricamente);

c) Pesquisas que partem dos agentes para as redes: muito mais complicado é entender os processos de formação de redes e a dinâmica dos agentes dentro delas. Principalmente no campo da economia, é fundamental identificar questões nas quais a adesão a redes seja economicamente relevante, por exemplo, a diferença de processos aleatórios e aqueles relativos à formação de "small world networks", em relação à racionalidade limitada dos agentes, algo muito próximo à economia comportamental. A pista para entender a dinâmica de formação das redes a partir do comportamento de agentes heterogêneos está no entendimento dos fenômenos de clusterização, o que se choca com a quase obsessão metodológica dos economistas em obter resultados gerais, médios ou, no máximo, que variam segundo os estratos da rede.

Finalmente, é importante relacionar os fenômenos de redes à ideia de camadas que são reveladoras de complexidade. A organização em níveis micro/meso/macro gera uma estrutura muito rígida ou geral, em relação ao conteúdo dos objetos que se deseja analisar. As redes de comércio cada vez mais são tratadas em camadas, assim como os estudos sobre a influência das redes sociais no comportamento dos indivíduos e das estruturas políticas. Métodos de tratamento de redes em camadas, redes multiplex, redes multicamadas, combinadas a processos de formação de clusters, e 
redes temporais constituem a fronteira do tema, e são capazes de gerar impactos expressivos nas ciências humanas (FAGIOLO, 2007; DICKISON, MAGNANI e ROSSI, 2016).

\section{Redes e Camadas no contexto da complexidade?}

Avanci (2018), realizando um estudo a nível global com patentes, identifica um conjunto de tecnologias habilitadoras que se tornam além de mais pervasivas, mais geradoras de oportunidades de mercado, cabendo destacar: mecânica avançada, biotecnologia - a agrícola, com um surpreendente destaque, dada as previsões da década de 90 de que os OGMs não passariam pelo crivo ambiental -, materiais avançados e fotônica. E como considerar a microeletrônica, que não se mostra tão destacada no estudo? Dada a importância radical da microeletrônica em quase todas as áreas de atividade econômica (considerando também o desempenho decepcionante da nanotecnologia), fica evidente que já ultrapassou a condição de tecnologia habilitadora de novas áreas e mercados.

Inovações de grande impacto referem-se a aplicações que interagem fortemente com a organização social, mesmo com a valorização simbólica de certos dispositivos e artefatos, o que não pode ser simplesmente subentendido como parte de funções de demanda. Um exemplo é a utilização de celulares por pequenos agricultores na redefinição das estruturas de intermediação no âmbito das transações de produtos. Configura-se um duplo movimento: a mudança na base tecnológica de muitos setores industriais, com maior intensidade de conhecimento científico e tecnológico, e a redefinição de padrões de consumo e de produção correntes, partindo de aplicações baseadas em dispositivos que já existem.

Vivemos um momento de redefinição fundamental das fontes de energia. De bens públicos geradores de monopólios naturais a estruturas extremamente descentralizadas, o campo da energia define as camadas dos sistemas técnico-econômicos, como apontado por Winskel et al. (2014), da seguinte forma: a) aquela referente à constituição tecnológica dos sistemas e sua variedade; b) os sistemas tecnológicos já consolidados, alguns já maduros, mas que podem ser impactados pelas mudanças originadas da difusão das novas combinações; c) os campos tecnológicos, como as diferentes modalidades de energias (será que faz sentido usar hoje o termo alternativo?); e d) o sistema sociotécnico. Ou seja, a importância dos arranjos institucionais e das organizações, assim como a evolução das rotinas e convenções, são cada vez mais percebidas em sua relevância. A discussão sobre o RenovaBio é um exemplo típico desse arranjo em camadas que é formado ao longo do processo de redefinição das fontes de energia.

Outro exemplo é a combinação de estudos sobre prospecção tecnológica em genômica, o uso de big data sobre clima e solo (no âmbito de uma região, de 
um país ou global) e as propostas de configuração de sistemas de crédito rural, visando, obviamente, à configuração de políticas com objetivos mais ambiciosos do que apenas cobrir o risco de produção de cultivos específicos. Esses processos formam camadas de conhecimento e de dados articulados, gerando trabalhos multi-instrumentais, que combinam vários tipos de ideias. A Universidade de Illinois sedia uma rede que em vários países organiza experimentos com dados que são coletados em tempo real e que permitem gerar recomendações de adubação com a dupla finalidade de reduzir o consumo de fertilizantes e também a poluição dos lençóis freáticos. Isso busca alterar rotinas de adubação na produção de milho utilizando o National Center of Supercomputing Applications (NCSA).

No campo de suporte às políticas de combate à desigualdade e à pobreza rural (a referência é o excelente trabalho coordenado por Alain de Janvry para o Banco Mundial em 2008), a economia agrícola ampliada passou a incorporar teoria dos jogos não-cooperativos e cooperativos e visões aplicadas da Nova Economia Institucional (notadamente os trabalhos de Ostrõm, Fafchamps, Balland, entre outros), para discutir questões de cooperação, exploração de recursos comuns e de gênero em comunidades de agricultores pobres, aproximando-se da área de pesquisa dos trabalhos de Bowles e Guintis sobre a emergência das formas cooperativas na economia.

Vale adicionar a crescente percepção de que, no mundo dos contratos, as formulações tradicionais, baseadas na ideia função de produção como suporte das decisões, necessitam incorporar a noção aportada por Alchian \& Demsetz de que a firma é um nexo de contratos e, com isso, a sequencialidade da produção importa no resultado. O que antes era "tomado como um dado" tornou-se fundamental tema de pesquisa. Allen e Lueck (2004) se aprofundam nessas questões no livro "The Nature of the Farm", contrapondo as decisões de internalizar etapas de produção agrícola em relação à contratação de serviços, tomando a Nova Economia Institucional - as noções de custos de transação e de governança - como referência. Todavia, os testes empíricos por eles realizados mostraram a insuficiência do uso da econometria para tratar do tema. A sequencialidade e a presença de modularidade nos processos produtivos exigem novos enfoques, como os aportados nos modelos N-K (FRENKEN, 2000).

Thomas Berger, professor da Universitat de Hohenheim, foi um dos pioneiros na combinação de camadas de dados relativos às condições físicas determinantes da produção com elementos que configuram as redes contratuais da produção agrícola. Uma aplicação da metodologia foi feita no estudo sobre os determinantes da difusão de sementes transgênicas, publicado na Revista de Economia e Agronegócio, que comprova a ideia bastante difundida entre agricultores de soja de que a flexibilidade na etapa de semeadura, propiciada pela adoção das variedades geneticamente modificadas, deu maior competitividade à produção no Mato Grosso (CARAUTA et al., 2017).

\section{Conclusões}


É claro que, para os cursos de pós-graduação, o ensino desses novos enfoques se torna um enorme desafio. Não basta passar para os alunos ensinamentos aprofundados de economia de produção e análise de equilíbrio parcial para entender o funcionamento dos mercados. Mesmo enfoques mais abrangentes, como os de Equilíbrio Geral Computável - que tem o grande mérito de ser pioneiro do uso e da organização de grande base de dados na agricultura -, sofrem limitações quando as camadas de dados geram interações não-lineares e resultados que contrariam o esperado pela teoria microeconômica.

Portanto, avanços conceituais devem ser acompanhados de avanços metodológicos, sob pena de se tornarem irrelevantes. Cabe a nós, então, incorporarmos esses novos temas e metodologias aos avanços da econometria e da economia nos últimos 30 anos.

\section{Referências}

ALLEN, D. LUECK, D. The Nature of the Farm: contracts, risks and organization in agriculture The MIT Press, Paperback, 280p, 2004

AVANCI, V. Análise de Bases de Conhecimento Industrial: evolução e pervasividade. 2018. 130p. Tese (Doutorado em Economia) - Programa de Pós-Graduação em Economia, Universidade Federal Fluminense, Niterói. Mimeo.

BARABÁSI, A. L.; ALBERT, R. Emergence of Scaling in Random Networks. Science, v. 286, n. 5439, p. 509-512, 15 out,. 1999.

BATAGELJ, V. et al. Understanding Large Temporal Networks and Spatial Networks: exploration, Pattern Searching, Visualization and Network Evolution. 1a ed. Vol. 2. John Wiley \& Sons, 2014.

CARAUTA et al. On-Farm Trade-Offs For Optimal Agricultural Practices In Mato Grosso, Brazil. Revista de Economia e Agronegócio, Universidade Federal de Viçosa, v. 15, n. 2017. <https://doi.org/10.25070/rea.v15i3.505>

CORREIDOIRA R.; BANERJEE, P. Measuring Patent's Influence on Technological Evolution: A Study of Knowledge Spanning as Driver of Inventive Activity. Research Policy. 44 (2), p. 508-521, 2014.

DICKISON, M. E.; MAGNANI, M. \& ROSSI, L. Multilayer Social Networks. Cambridge: Cambridge University Press. 203 p., 2016. Paperback.

FAGIOLO, G. Clustering in complex directed networks. Physical Review E, v. 76, n. 2, p. 026107, 2007.

FRENKEN, K. A complexity approach to innovation networks. The case of the aircraft industry (1909 - 1997). Research Policy, v. 29, n. 2, p.257-272, Feb. 2000.GOYAL, S. Connections: An introduction to the Economics of Networks. Princeton and Oxford: Princeton University Press, 2007. 
JACKSON, M. O. Social and Economic Networks. [S.1.]: Princeton University Press, 2010.

NAMATAME, A.; CHEN, S. Agent-based modeling and network dynamic. Oxford University Press, 1ª Ed., 332 p., 2016.

WINSKEL, M. et al. Learning pathways for energy supply technologies: Bridging between innovation studies and learning rates. Technological Forecasting and Social Change, v. 81, p. 96-114, 2014. 